(c) American Dairy Science Association, 2006.

\title{
Effects of Weaning and lonophore Supplementation on Selected Blood Metabolites and Growth in Dairy Calves
}

\author{
J. L. Klotz ${ }^{1}$ and R. N. Heitmann ${ }^{2}$ \\ Department of Animal Science, The University of Tennessee, Knoxville 37996
}

\begin{abstract}
Dairy calf weaning results in blood ketone concentrations in excess of mature rates of use and can result in excretion of ketones in urine representing a loss of energy. Lasalocid is frequently supplemented as an anticoccidial agent in calf starters; however, in mature ruminants it is known to alter molar ratios of ruminal volatile fatty acids (VFA). Effects of weaning transition and postweaning ionophore supplementation on body weight, dry matter (DM) intake, average daily gain (ADG), and blood concentrations of glucose, acetoacetate, $\beta$-hydroxybutyrate (BHBA), lactate, pyruvate, nonesterified fatty acids (NEFA), VFA, insulin, and glucagon were examined using Jersey bull calves $(\mathrm{n}=24)$ over 16 wk. Calves were blocked into groups of 2 according to birth date and weight and randomly assigned to receive either a commercial pelleted starter (control), or the same diet containing lasalocid (TRT; $83 \mathrm{mg} / \mathrm{kg}$ of DM). Calves were fed milk replacer from d 3 to 34 (d 3 to $20=454 \mathrm{~g} / \mathrm{d}$ at $12 \%$ solids; d 21 to $34=568 \mathrm{~g} /$ $\mathrm{d}$ at $15 \%$ solids), from $\mathrm{d} 35$ to 48 calves received both replacer (d 35 to $41=454 \mathrm{~g} / \mathrm{d} ; \mathrm{d} 42$ to $38=227 \mathrm{~g} / \mathrm{d}$ ) and free access to control or TRT starter, and from d 49 to 112 received ad libitum control or TRT. Body weight and jugular blood metabolite concentrations were measured and recorded weekly. Postweaning DM intake, average daily gain, and feed:gain did not differ between control and TRT calves. Glucose and NEFA concentrations did not differ between control and TRT, but declined with age. Insulin and glucagon concentrations did not differ between control and TRT, but glucagon concentrations increased with weaning. Total VFA significantly increased following introduction of solid feed at $\mathrm{d} 35$ in both groups with an apparent 1-wk lag in TRT VFA increases compared with control. Jugular acetate and butyrate concentrations were greater in control calves than TRT calves during wk 7. Propionate concentrations did not differ between control and TRT
\end{abstract}

Received August 23, 2005.

Accepted January 12, 2006.

${ }^{1}$ Current address: Forage-Animal Production Research Unit, ARS, USDA, Lexington, KY 40546.

${ }^{2}$ Corresponding author: rheitman@utk.edu at any time following weaning. Blood BHBA concentrations were greater in control than TRT during wk 8 and 9. Thus, consumption of starter supplemented with lasalocid delayed peak acetate and butyrate and lowered peak BHBA concentrations. However, supplementation at concentrations currently recommended for control of coccidiosis did not appear to be sufficient to enhance growth or efficiency during the wk 7 to 16 postweaning interval for this sample size.

Key words: dairy calf, ionophore, metabolism, weaning

\section{INTRODUCTION}

Rumen development in the young calf commences following initiation of dry feed intake, establishment of ruminal fermentation, and resultant VFA production (Tamate et al., 1962; Sutton et al., 1963). Butyrate is the most mitogenic of the 3 major ruminal VFA (Sakata and Tamate, 1976, 1978) and once absorbed, carbon from butyrate that is not oxidized to $\mathrm{CO}_{2}$ is extensively metabolized by the rumen epithelium to acetoacetate (AcAc) and BHBA before release into portal circulation (Bergman, 1990; Kristensen and Harmon, 2004). The ketogenic capacity of rumen epithelium has been shown to develop as early as $4 \mathrm{wk}$ of age and it occurs independently of the establishment of rumen fermentation (Giesecke et al., 1979; Lane et al., 2000). Quigley et al. (1991a) reported postweaning blood ketone concentrations that exceeded concentrations typically used as an indication of subclinical ketosis in mature animals (Bergman, 1984). Use of ketones by peripheral tissues follows first-order kinetics; i.e., it is a substrate concentration-dependent process. Once blood ketone concentrations exceed $2.0 \mathrm{mM}$, however, the system appears to achieve a maximum velocity (Leng, 1965; Bergman, 1971), and thereafter, small increases in ketone production rate will result in magnified increases in circulating concentrations. Ketone concentrations measured in the postweaning calf are in this range and could be a potential loss of energy at a developmental stage when energy is at a premium.

Supplementing animal feed with ionophores results in a variety of biological responses, many of which are advantageous to production efficiency (Bergen and 
Bates, 1984; Spears, 1990). Increases in production efficiency of cattle results from modification of rumen fermentation and selection against protozoa that cause coccidiosis (McGuffey et al., 2001). A widely recognized response associated with the supplementation of ionophores is the modification of ruminal VFA proportions. In studies using mature ruminants, supplementation generally results in greater ruminal propionate production at the expense of acetate and butyrate productions (Russell and Strobel, 1989).

Quigley et al. (1992) investigated the effects of lasalocid administered intraruminally in calves in the periweaning period up to $12 \mathrm{wk}$ of age. During the postweaning period, a reduction of circulating ketones due to lasalocid was observed, but concentrations in control animals were highest at the conclusion of the study. Thus, the age at which circulating concentrations decrease to adult levels was not apparent. The objectives of this experiment, therefore, were to examine the effects of weaning on selected metabolites in dairy calves from birth to $16 \mathrm{wk}$ of age and to determine the postweaning effect of lasalocid supplementation through a commercially available calf starter on blood metabolites, growth, intake, and efficiency.

\section{MATERIALS AND METHODS}

\section{Animals and Management}

Calves and Housing. All procedures were conducted under protocols approved by the University of Tennessee Animal Care and Use Committee (protocol \#1004). Twenty-four Jersey bull calves were obtained from the University of Tennessee Dairy Experiment Station (Lewisburg, TN) where they were maintained for the duration of the experiment. Calves received adequate colostrum intake ( 3 to $6 \mathrm{~L}$ in the first $12 \mathrm{~h}$, depending on birth weight) and were castrated before 3 $\mathrm{d}$ of age. Calves were individually housed in hutches on a bed of gravel with pens providing outdoor access for the duration of the experiment.

Diets and Feeding. Calves had ad libitum access to fresh water and trace-mineralized salt (Champions Choice, Cargill Inc., Minneapolis, MN) for the duration of the study. At $3 \mathrm{~d}$ of age, all calves received $227 \mathrm{~g}$ of commercial milk replacer brought to an approximate volume of $1.9 \mathrm{~L}$ with $\mathrm{H}_{2} \mathrm{O}$ (12\% solids; wt/vol; Instant Nursing Formula NT Medicated (oxytetracycline, 0.14 $\mathrm{g} / \mathrm{kg}$ and neomycin, $0.28 \mathrm{~g} / \mathrm{kg}$ ), Land O'Lakes Animal Milk Products Co., Fort Dodge, IA) twice daily from nipple bottles at 0800 and $1630 \mathrm{~h}$. At $21 \mathrm{~d}$ of age, the milk replacer ration was increased to $284 \mathrm{~g}$ ( $15 \%$ solids; wt/vol). At 5 wk of age (d 35), a commercial high-fiber calf starter (Calf Primer-I or Calf Primer-I-B; Tennessee Farmers Cooperative, La Vergne, TN) was offered for ad libitum consumption. At this time, the calves were still receiving milk replacer twice daily but reduced to only $227 \mathrm{~g}$. Starting at wk 6 (d 42), only the a.m. replacer ration was offered and at wk 7 (d 49), the calves were weaned. Calves with scours were treated with a commercial oral electrolyte solution (Revitilyte, Vets Plus, Inc., Knapp, WI) between the a.m. and p.m. milk replacer rations $(1200 \mathrm{~h})$ until symptoms dissipated.

Calf starter diets were commercially prepared and pelleted without (control; Calf Primer-I) or with (TRT; Calf Primer-I-B) lasalocid supplement ( $83 \mathrm{mg} / \mathrm{kg}$ of $\mathrm{DM})$. Calves were assigned sequentially as they were born to either control $(n=12)$ or TRT $(n=12)$ starter in blocks of 2. Calves within a block were less than 7 $\mathrm{d}$ apart in birth date (average difference $=2.4 \mathrm{~d}$; range $=$ 0 to $6 \mathrm{~d}$ ) and less than $5 \mathrm{~kg}$ apart in birth weight (average difference $=2.3 \mathrm{~kg}$; range $=0$ to $4.5 \mathrm{~kg}$ ). Starter diets were fed in a single ration at $0800 \mathrm{~h}$. When a calf consumed an entire previous day's ration, the ration was increased to $105 \%$ of the previous day's consumption. Feed rations and refusals were recorded daily.

\section{Measurements}

Calves were weighed weekly before the a.m. feeding for the entire experiment. Additional BW measures were also recorded at birth (before feeding colostrum), weaning, and termination. Feeds (milk replacer and calf starters) were sampled monthly and composited by lot number for subsequent composition analyses. Weekly blood samples were taken from the jugular vein for 16 wk between 0800 and $0900 \mathrm{~h}$. Sampling always occurred within $1 \mathrm{~h}$ postprandial to the a.m. ration distribution. Two 10-mL samples were collected in Vacutainer tubes (Becton-Dickinson and Co., Franklin Lakes, NJ) containing $\mathrm{K}_{3}$ EDTA ( $15 \%$ solution, 0.117 $\mathrm{mL}$ ). Samples were packaged in an insulated shipping container with cold packs and shipped overnight to Knoxville for next-day metabolite analysis.

\section{Chemical Analyses}

Blood Samples. Whole blood samples were analyzed for concentrations of glucose, L-(+)-lactate, pyruvate, AcAc, and BHBA. Analyses of samples for glucose, AcAc, and BHBA were performed on the day after sampling. Deproteinized lactate and pyruvate samples were centrifuged $\left(1,600 \times g\right.$ at $\left.4^{\circ} \mathrm{C}\right)$, and supernatants were harvested and frozen $\left(-20^{\circ} \mathrm{C}\right)$ for analysis within $2 \mathrm{wk}$. Plasma harvested from the remaining blood sample following centrifugation at $1,600 \times g$ at $4^{\circ} \mathrm{C}$ was aliquoted, and stored at $-20^{\circ} \mathrm{C}$ for later analysis of NEFA, VFA, glucagon, and insulin. 
Analyses for BHBA and AcAc were completed with enzymatic assays of Williamson and Mellanby (1974) and Mellanby and Williamson (1974), respectively. L(+)-Lactate and pyruvate concentrations were determined using procedures from Sigma kits for lactate and pyruvate (kit nos. 726-UV and 826-UV, Sigma Chemical Co., St. Louis, MO). Analysis of NEFA utilized the Wako NEFA-C kit (Wako Chemical USA, Dallas, TX). Blood glucose was determined using procedures from Sigma glucose kit (no. 510, Sigma Chemical Co.). Plasma glucagon and insulin were determined using the double antibody radioimmunoassay and the Coat-A-Count insulin kits and protocols of Diagnostics Products Corporation (Los Angeles, CA). For insulin, glucagon, and NEFA analyses, intraassay errors greater than $10 \%$ were not accepted and samples were rerun. For these analytes, all samples were analyzed in single runs with intraassay variation $<8 \%$. Plasma VFA were analyzed by the procedure described by Reynolds et al. (1986) and modified by Quigley et al. (1991b) and Benson et al., (2002) using a Hewlett Packard gas chromatograph (5890A), auto-sampler (7637A), integrator (3393A), and a J\&W Scientific 530- $\mu \mathrm{m}$ HP-FFAP capillary column (Agilent Technologies Inc., Palo Alto, CA).

Feed Samples. Composite dietary samples of control and TRT starter were ground through a $1-\mathrm{mm}$ screen in a Wiley mill (Arthur H. Thomas Co., Philadelphia, PA) and analyzed with composite milk replacer samples for DM, N (model FP-2000 nitrogen analyzer, Leco, St. Joseph, MI), gross energy (model 1241 adiabatic calorimeter, Parr Instruments, Moline, IL), ether extract (AOAC, 1999), NDF, ADF (Ankom Technology, 2003a,b; Ankom 200 series fiber analyzer, Ankom Technology Corp., Macedon, NY), and minerals (Unicam Solaar 969, atomic absorption spectrometer, Unicam, Cambridge, UK).

\section{Statistical Analyses}

Data for weekly BW and blood variables were analyzed statistically as a randomized complete block design for the effect of age (week) and dietary treatment (starter with or without lasalocid) using the mixed model procedures of SAS [version 8.2 (2000), SAS Inst., Inc., Cary, NC]. As the experimental units, calves $(\mathrm{n}=$ 24) did not start the project simultaneously; thus, calves were blocked on birth date and birth weight in groups of 2 . The statistical model used was

$$
\begin{gathered}
\mathrm{Y}_{\mathrm{ijk}}=\mu+\beta_{\mathrm{i}}+\mathrm{D}_{\mathrm{j}}+\beta \times \mathrm{D}_{\mathrm{ij}}+\mathrm{W}_{\mathrm{k}}+\mathrm{W} \times \mathrm{D}_{\mathrm{jk}} \\
+\beta \times \mathrm{D} \times \mathrm{W}_{\mathrm{ijk}}
\end{gathered}
$$

where $\mathrm{Y}_{\mathrm{ijk}}=$ dependent variables; $\mu$ = overall mean; $\beta_{\mathrm{i}}=$ effect of block i; $D_{j}=$ effect of diet $j ; \beta \times D_{i j}=$ effect of diet by block (error term for diet); $\mathrm{W}_{\mathrm{k}}=$ effect of week $\mathrm{k}$ (age); $\mathrm{W} \times \mathrm{D}_{\mathrm{jk}}=$ effect of week by diet interaction; and $\beta \times \mathrm{W} \times \mathrm{D}_{\mathrm{ijk}}=$ error term for week and week by diet (residual).

Because the age of a calf across the 16 sampling weeks is a treatment whose order was fixed by definition, a repeated measures model over time was included as a treatment design, with diet as a between-subject factor and week as a within-subject factor. Because the dietary treatment did not commence until wk 5, the sampling period of wk 1 to 4 was analyzed separately to ensure that any observed effects were not the result of preexisting conditions. There were no differences detected in blood variables or BW measured before initiation of dietary treatment at wk 5 , so results presented include analysis across all $16 \mathrm{wk}$.

Similar to factors described above, data for birth (d 0 ), weaning (d 49), and termination (112 d) weights; preweaning, postweaning, and overall average daily gain (ADG); postweaning feed efficiency, and DMI were analyzed as a randomized complete block design for effect of dietary treatment. Class variables were diet and block, but there was no week effect or repeated measures treatment design included in the analysis of these data. Consequently, the error term for analysis of these variables was block $\times$ diet. Because the number of calves per treatment was determined from power calculations based on the standard deviations of metabolites measured in this study, the number of calves required to detect a statistically significant response between treatments for these production measures is likely greater than what was actually used in this experiment.

Death of a TRT calf between the eighth and ninth sampling periods created an incomplete block; therefore, this block was removed from the study. Also, 2 separate instances where samples were damaged during shipping resulted in additional missing observations; thus, results presented are least squares means. Blood variables, weekly BW, and postweaning measures of ADG, feed efficiency, and termination weights were analyzed using 22 calves. Measures of birth weight, weaning weight, and ADG from birth to weaning were analyzed using all 24 calves.

Due to heterogeneous variance causing abnormal distribution, blood variables propionate, butyrate, and insulin were rank transformed using the RANK procedure of SAS (SAS Institute, 2000) to improve normality. This resulted in data for these variables being ranked by block and ANOVA performed on ranks for least squares means separation. Least squares means separation was done using least significant difference features in SAS. Probabilities of $P<0.05$ are discussed as significant throughout, unless otherwise noted. 
Table 1. Measured chemical composition of feeds ${ }^{1}$

\begin{tabular}{lccc}
\hline & $\begin{array}{l}\text { Milk } \\
\text { replacer }\end{array}$ & Control & Treatment $^{3}$ \\
\hline DM, \% & 93.3 & 89.9 & 90.7 \\
CP, \% & 23.0 & 19.8 & 19.4 \\
Ether extract, \% & 17.5 & 3.2 & 2.9 \\
NDF, \% & 0.17 & 34.5 & 33.9 \\
ADF, \% & 0.03 & 19.0 & 19.1 \\
Ash, \% & 11.9 & 8.4 & 8.4 \\
Calcium, g/kg & 7.2 & 11.6 & 10.6 \\
Phosphorus, g/kg & 9.8 & 8.3 & 8.0 \\
Magnesium, g/kg & 1.6 & 3.5 & 3.6 \\
Potassium, g/kg & 27.7 & 13.8 & 13.2 \\
Gross energy, Mcal/kg & 4.9 & 4.4 & 4.3 \\
\hline
\end{tabular}

${ }^{1}$ Milk replacer was Instant Nursing Formula (Land O'Lakes, Fort Dodge, IA) and calf starters were Calf Primer I (control) and Calf Primer I-B (treatment); Tennessee Farmers Cooperative, Lavergne, TN.

${ }^{2}$ Composition on a DM basis.

${ }^{3}$ Treatment calf starter formulated to contain lasalocid at $83 \mathrm{mg} /$ $\mathrm{kg}$ of DM.

\section{RESULTS}

Overall, calves remained healthy throughout the study. Scours was limited to the preweaning portion of the experiment and occurred in all but one calf (TRT); the average duration was $6.8 \pm 3.5$ and $6.1 \pm 3.6 \mathrm{~d}$ for control and TRT, respectively. Two calves (control) developed pinkeye within their second week on the experiment and were treated accordingly (Gentocin spray and LA-200, Pfizer, New York, NY). One calf within the 12th block in the TRT group died of unknown causes at $8 \mathrm{wk}$ of age resulting in the removal of this block from the presented data. No other health-related problems were noted following weaning and, due to nearly identical weaning weights, it is unlikely that any negative health effects from the preweaning period compromised the postweaning treatment comparisons.

Results of analysis of chemical composition of milk replacer and control and TRT calf starters are in Table 1. All components for all feeds agreed with the ranges specified by the manufacturer. There were no apparent differences in analyses of composition between control and TRT calf starters.

\section{$B W, D M I$, and Efficiency of Gain}

Calves had similar birth and weaning BW (Table 2) and wk 1 to $4 \mathrm{BW}$ (Figure 1). Thus, no pretreatment differences were present to influence measurements taken after dietary treatment was initiated at wk 5 . Average daily gain calculated from birth to weaning includes the 2 -wk adaptation period in which calves were receiving milk replacer in addition to the control or TRT calf starter, but did not differ by dietary assignment. Final (16-wk) BW, ADG from weaning to $16 \mathrm{wk}$,
Table 2. Means for BW, DMI, average daily gain (ADG), and efficiency of gain for calves fed calf starter with or without lasalocid pre- and postweaning

\begin{tabular}{lclll}
\hline Variable $^{1}$ & Control & Treatment & SE & $P<^{2}$ \\
\hline BW, kg & & & & \\
Birth (d 0) & 25.06 & 25.89 & 0.84 & 0.31 \\
Wean (d 49) & 35.30 & 34.77 & 1.27 & 0.67 \\
Final (d 112) & 83.90 & 81.47 & 2.71 & 0.39 \\
ADG, kg/d & & & & \\
Birth to final (d 0 to 112) & 0.53 & 0.50 & 0.02 & 0.13 \\
Birth to wean (d 0 to 49) & 0.21 & 0.18 & 0.02 & 0.22 \\
Wean to final (d 49 to 112) & 0.78 & 0.75 & 0.03 & 0.47 \\
DMI, kg/d & 2.35 & 2.34 & 0.07 & 0.92 \\
Feed:gain $^{3}$ & 3.10 & 3.19 & 0.11 & 0.44 \\
\hline
\end{tabular}

${ }^{1}$ Final BW, ADG birth to final, ADG wean to final, DMI, and feed:gain measurements are $n=11$ per dietary treatment. All other observations are $\mathrm{n}=12$ per dietary treatment.

${ }^{2}$ Probability of greater $F$ for the effect of dietary treatment on variable; not significant at $P>0.10$.

${ }^{3}$ Calculated from postweaning period data, thus represents period from weaning to finish (d 49 to 112).

$\mathrm{ADG}$ from birth to $16 \mathrm{wk}$, postweaning DMI, and feed:gain were not different between control and TRT calf starters (Table 2). Weekly BW increased with similar trends between control and TRT calves (Figure 1). There was a significant week effect $(P<0.01)$ and a tendency $(P=0.10)$ for a diet effect from wk 5 to 16 . Before initiation of dietary treatment, BW measures overlapped. Introduction of dry feed caused an apparent change in the slope of BW gain between wk 5 and 7 where the lines diverged slightly and TRT BW remained slightly lower but increased in parallel with control through wk 16. Body weights for the control-

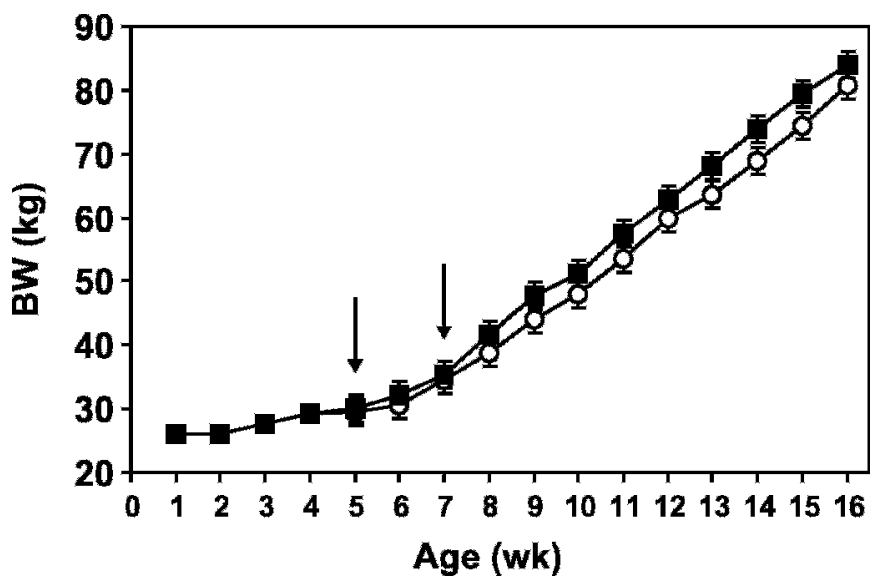

Figure 1. Effects of calf starter supplemented with $(\bigcirc)$ or without lasalocid ( $\mathbf{0}$ ) on weekly BW. Arrows indicate initiation of starter ration at wk 5 and cessation of milk replacer ration at wk 7 . Weeks 1 to 4 are means \pm SE for 22 calves. From wk 5 to 16 effect of diet tended to differ $(P=0.10)$, and all values are means $(\mathrm{n}=11$ per treatment) $\pm \mathrm{SE}$. 


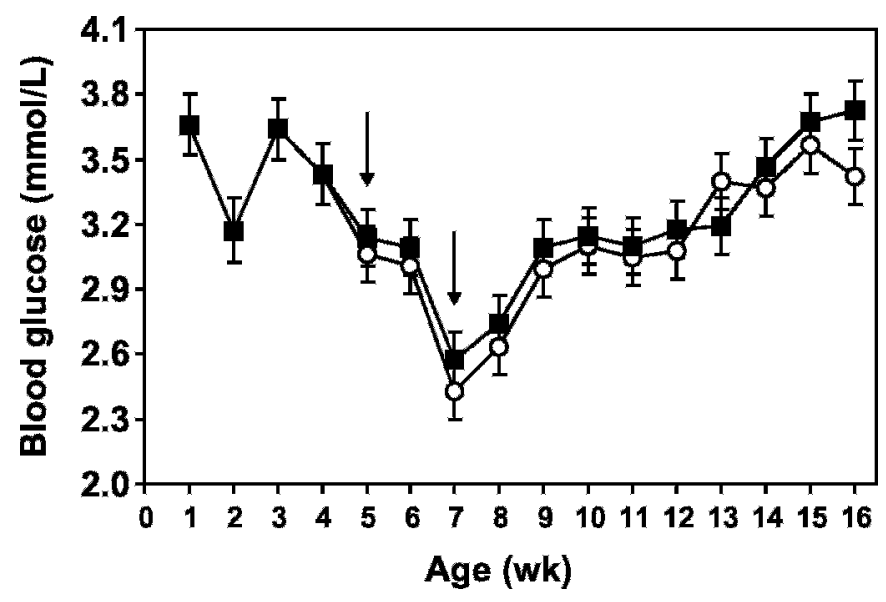

Figure 2. Effects of calf starter supplemented with $(\bigcirc)$ or without lasalocid ( $)$ on weekly glucose concentrations. Arrows indicate initiation of starter ration at wk 5 and cessation of milk replacer ration at wk 7 . Weeks 1 to 4 are means \pm SE for 22 calves. From wk 5 to 16 all values are means $(n=11$ per treatment $) \pm S E$.

fed calves became greater $(P<0.05)$ than TRT calves during wk 14 and 15 (Figure 1).

\section{Blood Metabolites}

Glucose and NEFA. Concentrations of blood glucose were not significantly affected by treatment, but week effect was significant (Figure 2). The ANOVA for diet and diet $\times$ week interaction were not significant. There was no postweaning effect of supplementation on glucose observations. Concentrations for both treatments decreased with age, reaching a nadir at wk 7 and 8 (2.5 and $2.7 \mathrm{mmol} / \mathrm{L}$, respectively), which coincided with weaning. Concentrations began to increase and by wk 15 and $16(3.6 \mathrm{mmol} / \mathrm{L})$ were similar to levels observed at wk $1(3.7 \mathrm{mmol} / \mathrm{L})$.

Concentrations of plasma NEFA were not affected by postweaning ionophore supplementation (Figure 3). Both diet and week effects were apparent $(P<0.01)$, but a diet $\times$ week interaction was not significant. Although there was no difference between control and TRT at individual week, there was a large drop between wk 5 and $8(0.27$ and $0.16 \mathrm{mmol} / \mathrm{L}$, respectively). Like that in glucose, this nadir coincided with the cessation of milk replacer rations. Concentrations of preweaning NEFA (wk 1 to7) were greater than those taken postweaning (wk 8 to $16 ; P<0.05$ ).

Ketones. Concentrations of AcAc were highly variable and although week effect was significant, there was no apparent trend (Figure 4). There were no observed differences between diets or between pre- and postweaning. Circulating concentrations of BHBA were more dynamic than AcAc across the 16-wk experimen-

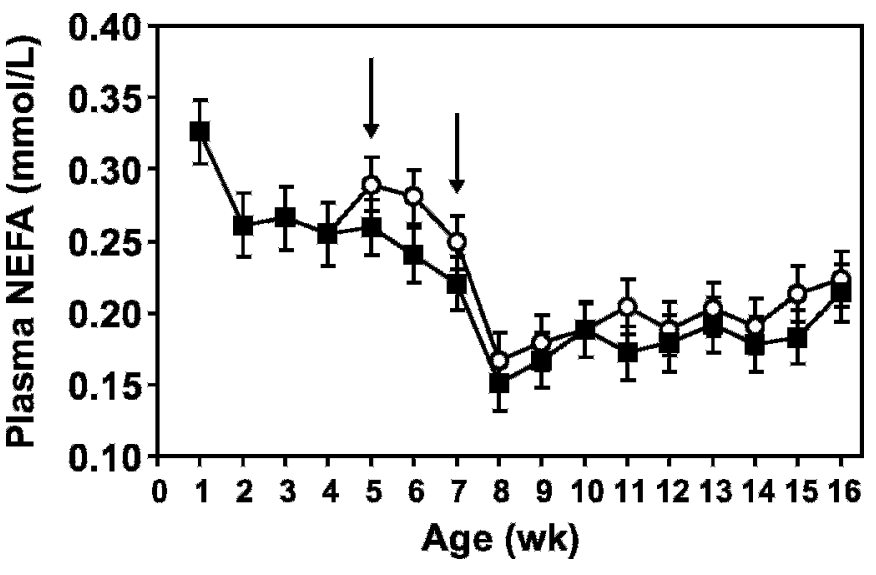

Figure 3. Effects of calf starter supplemented with $(\bigcirc)$ or without lasalocid (ם) on weekly NEFA concentrations. Arrows indicate initiation of starter ration at wk 5 and cessation of milk replacer ration at wk 7 . Weeks 1 to 4 are means \pm SE for 22 calves. From wk 5 to 16 effect of diet was significant $(P<0.05)$, and all values are means $(\mathrm{n}=11$ per treatment $) \pm \mathrm{SE}$.

tal period (Figure 5). The effect of week was significant, but neither diet nor diet $\times$ week interaction effects were significant. When all calves were receiving milk replacer, blood BHBA concentrations were constant (0.1 $\mathrm{m} M$ for wk 1 to 4 ). During the adaptation period between wk 5 and 7, there was an evident increase in both control and TRT. By wk 8, concentrations of BHBA in calves receiving the control starter had increased 5fold $(0.99 \mathrm{mmol} / \mathrm{L})$ from the 5 -wk concentrations $(0.18$ $\mathrm{mmol} / \mathrm{L})$ and reached a zenith at wh $9(1.12 \mathrm{mmol} /$ L). Calves receiving the TRT starter had lower BHBA concentrations than control during wk 8 and 9 (0.73

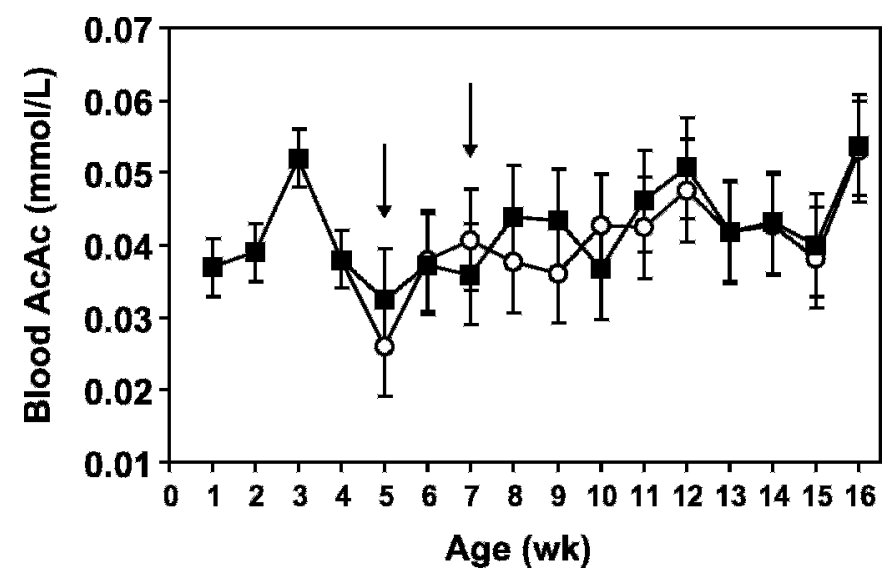

Figure 4. Effects of calf starter supplemented with $(\bigcirc)$ or without lasalocid ( $)$ on weekly acetoacetate (AcAc) concentrations. Arrows indicate initiation of starter ration at wk 5 and cessation of milk replacer ration at wk 7 . Weeks 1 to 4 are means \pm SE for 22 calves. From wk 5 to 16 all values are means $(n=11$ per treatment $) \pm S E$. 


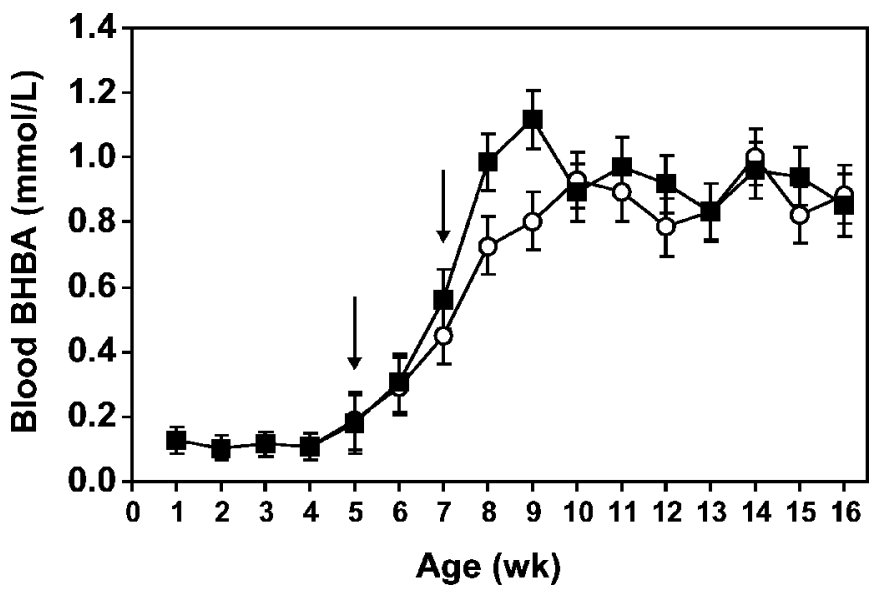

Figure 5. Effects of calf starter supplemented with $(O)$ or without lasalocid ( $)$ on weekly BHBA concentrations. Arrows indicate initiation of starter ration at wk 5 and cessation of milk replacer ration at wk 7. Weeks 1 to 4 are means $\pm \mathrm{SE}$ for 22 calves. From wk 5 to 16 all values are means $(n=11$ per treatment $) \pm S E$.

and $0.80 \mathrm{mmol} / \mathrm{L}$, respectively) and appeared to reach an asymptote at wk $10(0.93 \mathrm{mmol} / \mathrm{L})$. Concentrations from wk 10 to 16 ranged between 0.8 and $1.0 \mathrm{mmol} / \mathrm{L}$ and did not differ between week or diet.

VFA. Plasma concentrations of acetate measured across 16 wk are presented in Figure 6. Both effects of diet and week were significant for acetate, but diet $x$ week interaction was not. Before wk 5 , concentrations of acetate were stable and remained at or below 0.2 $\mathrm{mmol} / \mathrm{L}$ for all calves. After dry feed intake was initiated (wk 5), an increase similar to BHBA was observed. At

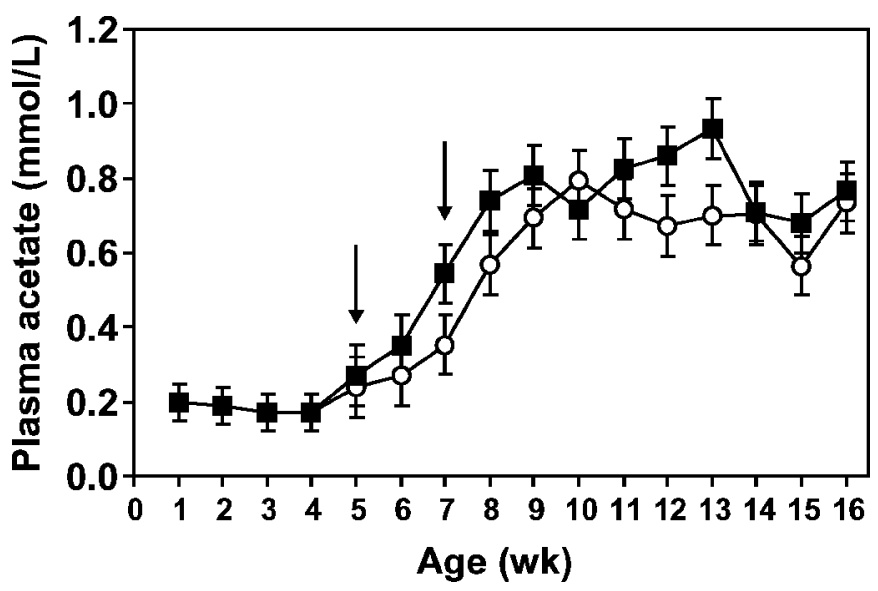

Figure 6. Effects of calf starter supplemented with $(\bigcirc)$ or without lasalocid ( $\square$ ) on weekly acetate concentrations. Arrows indicate initiation of starter ration at wk 5 and cessation of milk replacer ration at wk 7 . Weeks 1 to 4 are means $\pm \mathrm{SE}$ for 22 calves. From wk 5 to 16 effect of diet was significant $(P<0.05)$ and all values are means $(\mathrm{n}=11$ per treatment $) \pm \mathrm{SE}$.

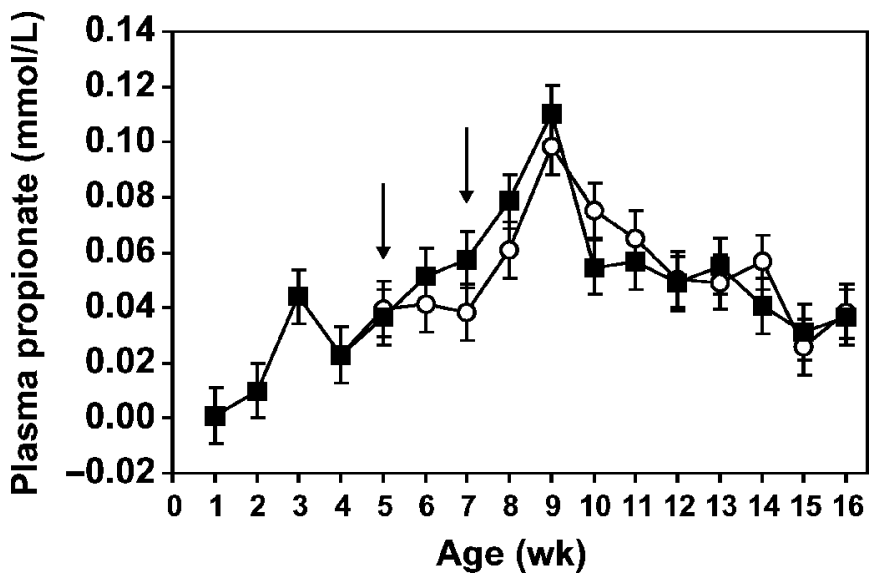

Figure 7. Effects of calf starter supplemented with $(\bigcirc)$ or without lasalocid (ם) on weekly propionate concentrations. Arrows indicate initiation of starter ration at wk 5 and cessation of milk replacer ration at wk 7 . Weeks 1 to 4 are means \pm SE for 22 calves. From wk 5 to 16 all values are means $(n=11$ per treatment $\pm \mathrm{SE}$.

weaning (wk 7), acetate concentrations of calves receiving control starter $(0.54 \mathrm{mmol} / \mathrm{L})$ tended to be greater than calves receiving TRT $(0.35 \mathrm{mmol} / \mathrm{L} ; P<0.10)$. Concentrations of acetate (Figure 6) for control and TRT continued to increase after weaning in a similar manner, but control was not significantly greater than TRT until wk $13(P<0.05)$. Like BHBA (Figure 5$)$, the postweaning increase in acetate concentrations for TRT group appeared to be delayed and have a lower maximum concentration relative to control.

Plasma concentrations of propionate did not differ between calf starter treatments (Figure 7). There was a significant week effect, but diet and diet $\times$ week were not significant. Concentrations increased considerably at weaning (wk 7) and both control and TRT groups reached a zenith at wk $9(0.11$ and $0.09 \mathrm{mmol} / \mathrm{L}$, respectively). After wk 9, concentrations began to decline in similar manner for both groups and reached concentrations at wk $16(0.04 \mathrm{mmol} / \mathrm{L})$ that were similar to those measured at wk 5 .

Plasma butyrate concentrations before wk 6 remained at or below $0.004 \mathrm{mmol} / \mathrm{L}$ (Figure 8). Like propionate, the effect of week was significant, but not of diet or diet $\times$ week. During the adaptation period between wk 5 and 7 , there was a 7 -fold increase in butyrate for control $(0.002$ to $0.011 \mathrm{mmol} / \mathrm{L})$, but only a 2 -fold increase in TRT (0.003 to $0.006 \mathrm{mmol} / \mathrm{L}$ ). Butyrate concentrations at wk 7 tended to be greater in control than TRT $(P=0.09)$. Butyrate concentrations at wk 7 in TRT decreased from those measured at wk 6 and this may be responsible for the observed difference. Maximum plasma butyrate for the control group was measured at wk $9(0.017 \mathrm{mmol} / \mathrm{L})$, whereas TRT concentrations 


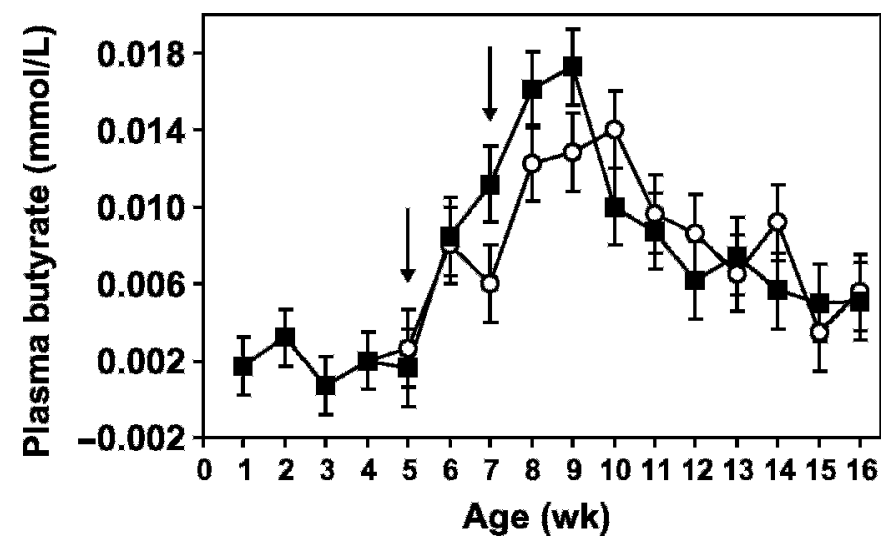

Figure 8. Effects of calf starter supplemented with $(O)$ or without lasalocid ( on weekly butyrate concentrations. Arrows indicate initiation of starter ration at wk 5 and cessation of milk replacer ration at wk 7 . Weeks 1 to 4 are means $\pm \mathrm{SE}$ for 22 calves. From wk 5 to 16 all values are means $(n=11$ per treatment $) \pm S E$.

peaked at wk $10(0.014 \mathrm{mmol} / \mathrm{L})$. Similar to plasma propionate, butyrate concentrations began a decline after each zenith and continued through wk 16 for both control and TRT.

Lactate and Pyruvate. Concentrations of blood lactate and pyruvate had a significant week effect, but diet effects and diet $\times$ week interactions were not significant for either metabolite (Figures 9 and 10, respectively). The effect of weaning generated no response in either metabolite. Lactate and pyruvate concentrations were highest during wk $12(1.87$ and $0.25 \mathrm{mmol} / \mathrm{L}$, respectively) and lactate concentrations were generally 6- to 8-fold greater than pyruvate across the 16 -wk period. Lactate concentrations for control and TRT ap-

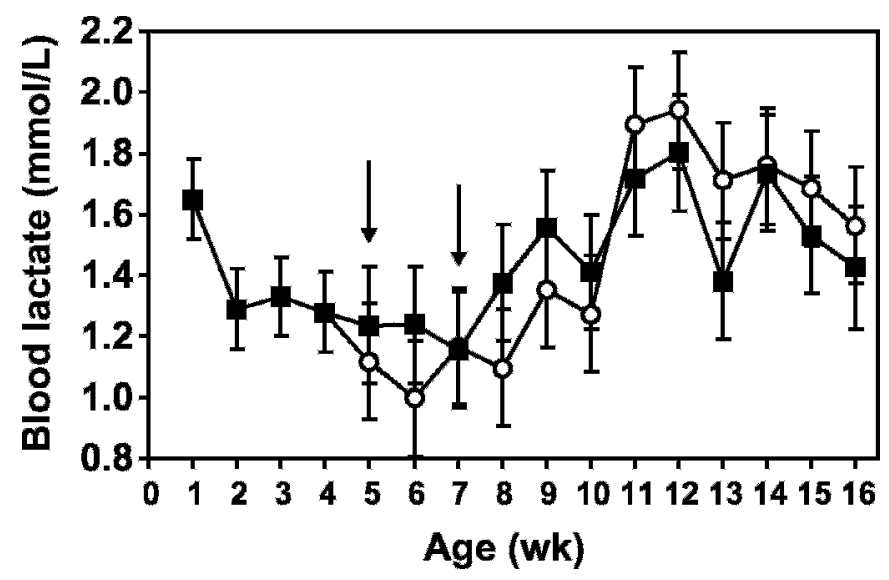

Figure 9. Effects of calf starter supplemented with $(\bigcirc)$ or without lasalocid ( $)$ on weekly lactate concentrations. Arrows indicate initiation of starter ration at wk 5 and cessation of milk replacer ration at wk 7 . Weeks 1 to 4 are means \pm SE for 22 calves. From wk 5 to 16 all values are means $(n=11$ per treatment $) \pm S E$.

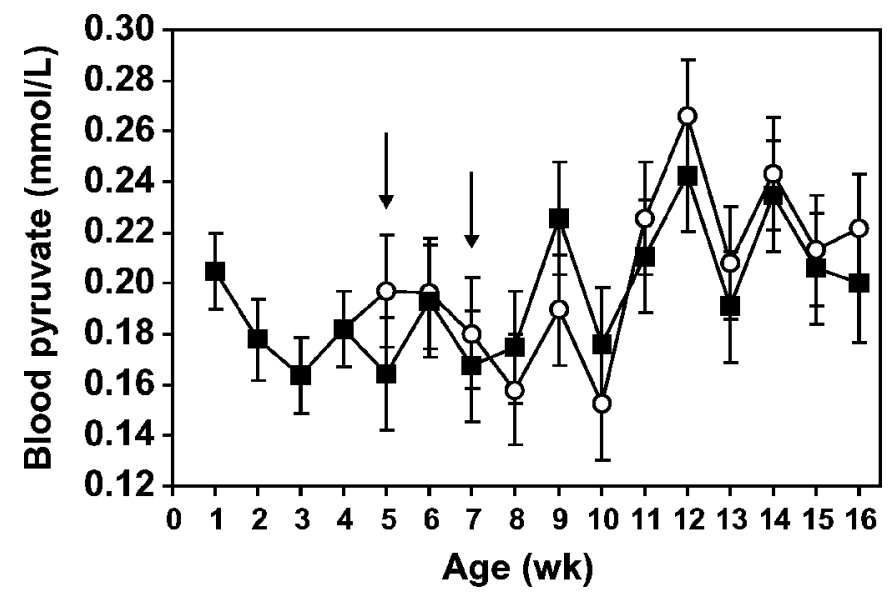

Figure 10. Effects of calf starter supplemented with $(\bigcirc)$ or without lasalocid (ם) on weekly pyruvate concentrations. Arrows indicate initiation of starter ration at wk 5 and cessation of milk replacer ration at wk 7 . Weeks 1 to 4 are means \pm SE for 22 calves. From wk 5 to 16 all values are means $(n=11$ per treatment $) \pm \mathrm{SE}$.

peared to remain elevated wk 11 through wk 16 (Figure 9 ). This coincided with the period when propionate concentrations were declining (Figure 7).

Insulin and Glucagon. Plasma concentrations of insulin were variable across all $16 \mathrm{wk}$ of the experiment (Figure 11). There was a significant week effect for insulin, but diet and diet $\times$ week were not significant across the 16 -wk period. The control group exhibited dynamic changes in preweaning concentrations during the adaptation period. The TRT group had a steadier decline from wk $1(22.8 \mathrm{pmol} / \mathrm{L})$ to a nadir at wk 7 (1.4 $\mathrm{pmol} / \mathrm{L})$. The concentrations of TRT insulin increased

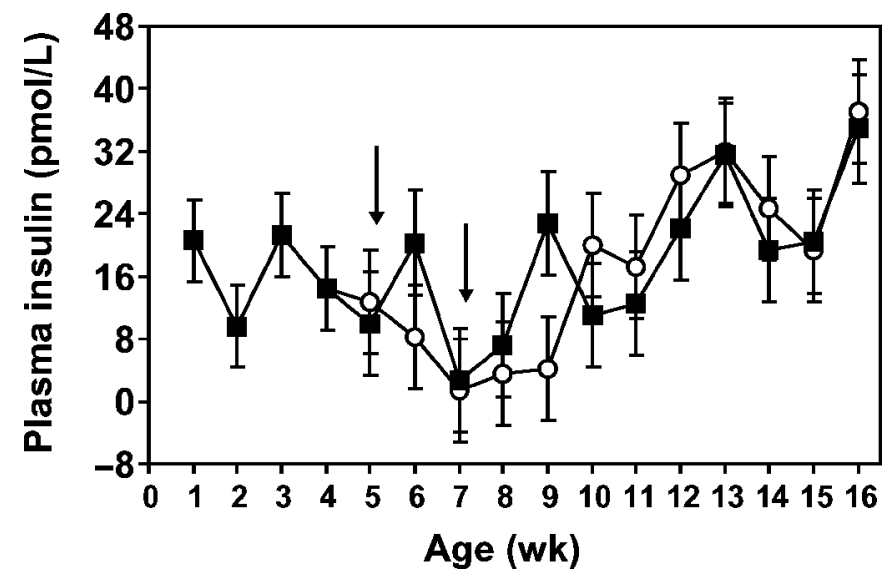

Figure 11. Effects of calf starter supplemented with $(\bigcirc)$ or without lasalocid ( $)$ on weekly insulin concentrations. Arrows indicate initiation of starter ration at wk 5 and cessation of milk replacer ration at wk 7 . Weeks 1 to 4 are means \pm SE for 22 calves. From wk 5 to 16 all values are means $(n=11$ per treatment $) \pm S E$. 


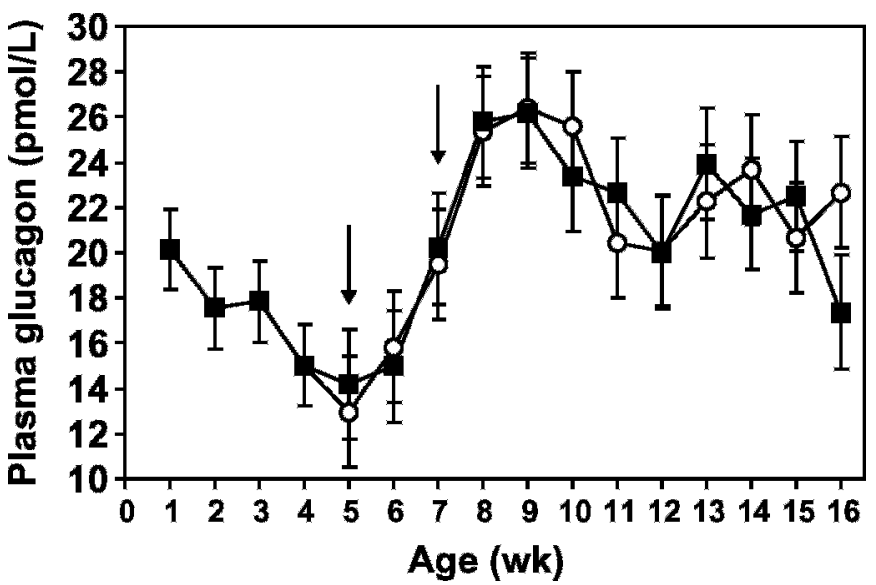

Figure 12. Effects of calf starter supplemented with $(\bigcirc)$ or without lasalocid ( $\square$ ) on weekly glucagon concentrations. Arrows indicate initiation of starter ration at wk 5 and cessation of milk replacer ration at wk 7 . Weeks 1 to 4 are means \pm SE for 22 calves. From wk 5 to 16 all values are means $(n=11$ per treatment $) \pm S E$.

after wk 7 and reached a maximum at wk $16(37.0 \mathrm{pmol} /$ L). Measured plasma concentrations of glucagon were less variable than insulin and exhibited a response to the dietary regimen change at weaning (Figure 12). There was a significant week effect for glucagon, but diet and diet $\times$ week were not significant across the 16wk period. Glucagon was at the lowest concentration at wk $5(13.6 \mathrm{pmol} / \mathrm{L})$ and then sharply increased to a maximum concentration for wk 8, 9, and 10 (25.6, 26.3, and $24.5 \mathrm{pmol} / \mathrm{L}$, respectively). Before wk 5 , the ratio of insulin and glucagon was approximately 1 to 1 , but glucagon became the more predominant circulating peripheral hormone postweaning and the ratio was frequently below 1 .

\section{DISCUSSION}

\section{Diets and Calf Performance}

Chemical analysis of both calf starters (Table 1) met or exceeded recommended levels (NRC, 2001) and both starters were similar in components that corresponded with the ranges listed in the guaranteed analysis of the manufacturer. The starters used in this experiment were complete feeds containing high-fiber byproducts designed to stimulate ruminal development and to be fed as the sole feed. Birth weights and weaning weights (Table 2) were similar to other studies using Jersey calves (Quigley, 1996; Stanley et al., 2002). Previous performance studies summarized by Chalupa (1980) demonstrated that lasalocid and monensin produced a small reduction of intake, an increase in ADG, and improved feed efficiency (intake/gain) when compared with controls. These observations, however, were made primarily with feedlot cattle. Anderson et al. (1988) reported that Holstein calves fed lasalocid from $4 \mathrm{~d}$ of age to $12 \mathrm{wk}$ of age had greater feed intake and weight gain after 5 wk of age. Conversely, Eicher-Pruiett et al. (1992) reported increased daily gain in Holstein calves with lasalocid supplementation to be greatest during the first 6 wk. Similar to the current data, Quigley et al. (1992) and Steen et al. (1992) observed no effects of lasalocid administration on BW, ADG, or feed efficiency in Holstein bull calves or Holstein heifers, respectively.

The disparity in reported effects of lasalocid supplementation on gain and intake is likely a result of differences in supplementation dosage, supplementation vehicle, and experimental timelines. All 3 studies (Anderson et al., 1988; Eicher-Pruiett et al., 1992; Quigley et al., 1992) supplemented lasalocid within liquid and solid diets, but Quigley et al. (1992) supplemented via rumen cannula instead of with feed. Dosage of lasalocid could be another effect causing the findings to differ. Eicher-Pruiett et al. (1992) concluded that daily intake of lasalocid concentrations greater than $1.0 \mathrm{mg} / \mathrm{kg}$ of BW were most effective and should be delivered in all feeds (milk replacer, prestarter, and starter). Quigley et al. (1992) only included lasalocid in milk replacer, or through direct ruminal infusion and used $1.0 \mathrm{mg} / \mathrm{kg}$ of BW (not greater than $1.0 \mathrm{mg} / \mathrm{kg}$ as suggested by Eicher-Pruiett et al., 1992). Anderson et al. (1988) supplemented lasalocid in milk replacer $(0.5$ to $1.0 \mathrm{mg} / \mathrm{kg}$ of BW), in prestarter ( $88 \mathrm{mg} / \mathrm{kg}$ as fed) and starter (44 $\mathrm{mg} / \mathrm{kg}$ as fed). However, Anderson et al. (1988) reported that there were periods in which calves were consuming 2 feed types, both supplemented with ionophore, thus receiving a larger combined daily dosage (range reported 0.4 to $1.6 \mathrm{mg} / \mathrm{kg}$ of $\mathrm{BW}$ per d). In the current study, lasalocid was supplemented only in the calf starter and the dosage was dependent on intake of the animal $(75 \mathrm{mg} / \mathrm{kg}$ as fed or $83 \mathrm{mg} / \mathrm{kg}$ of DM). Concentrations supplemented in this study were close to the amount supplemented by Anderson et al. (1988) in prestarter. Eicher-Pruiett et al. (1992) also reported that lasalocid supplemented only in prestarter and starter combined and starter alone resulted in less gain and intake than control calves or calves receiving lasalocid in all 3 diet types. This observation is similar to results of the current study, where TRT calves were always numerically lower than control in weekly BW (Figure 1), although DMI was the same.

\section{Blood Metabolites}

Preruminant blood glucose concentrations $(5.3 \mathrm{mmol} /$ L in lambs; Leat, 1970) are higher than those of mature ruminants ( $2.7 \mathrm{mmol} / \mathrm{L}$ in sheep; Bergman, 1971), but decrease to adult values at approximately 3 mo of age. 
This decline appears to be independent of ruminal development or diet and thus, is probably caused by declining alimentary hyperglycemia associated with absence of milk and loss of glucose from erythrocytes (Leat, 1970). Preweaning blood glucose concentrations in the present study were low by comparison. Although the lowest glucose concentrations (Figure 2) approximated $2.5 \mathrm{mmol} / \mathrm{L}$, the preweaning concentrations ranged from 3.3 to 3.8 , and were lower than other reports.

Stanley et al. (2002) reported blood glucose concentrations of 4.7 and $4.4 \mathrm{mmol} / \mathrm{L}$ at 1 and $2 \mathrm{wk}$ of age for Jersey calves and 5.1 and $4.8 \mathrm{mmol} / \mathrm{L}$ for Holstein calves. Quigley et al. (1991a) reported glucose concentrations between 6.3 and $5.8 \mathrm{mmol} / \mathrm{L}$ for Holstein calves at 1 and $2 \mathrm{wk}$ of age and a nadir of $4.2 \mathrm{mmol} / \mathrm{L}$ at 9 wk. At 16 wk of age, previously reported concentrations of glucose in Holstein calves ranged from 4.5 to 5.0 $\mathrm{mmol} / \mathrm{L}$ (Quigley et al., 1991a; Quigley and Bernard, 1992). Quigley and Bernard (1992) sampled calves $0 \mathrm{~h}$ after feeding, similar to the periprandial sampling of the current study, and glucose concentrations were lower than the 2 -h postprandial measures in the experiment. These values for 0 -h glucose were presented graphically from 0 to $112 \mathrm{~d}$ and exhibited a similarshaped curve to that in Figure 2 with a dip in concentrations around weaning and a gradual increase to wk 16. Lower than normal glucose concentrations in the current study appear to be constant across all $16 \mathrm{wk}$ and can probably be attributed to the time of sampling in relation to feeding and the 24-h shipment period that occurred before analysis. This reduction in glucose concentration appeared constant for all measures and suggests that detection of significant differences pertaining to effects of age and diet should remain unaffected.

Propionate is a potent glucogenic compound and is the only VFA that is a glucose precursor (Bergman, 1971, 1990). Thus, as a calf undergoes ruminal maturation, dwindling concentrations of dietary glucose are increasingly replaced by glucogenic compounds such as propionate. Propionate concentrations presented in Figure 7 resemble an inverted version of the glucose concentrations in Figure 2. Glucose concentrations had reached the lowest concentrations of the experiment at wk 7 and this coincided with increasing propionate concentrations, which peaked at wk 9 . The sudden increase in plasma propionate concentration in Figure 7 was concurrent with weaning and is comparable to other reports in calves (Quigley et al., 1991b).

Anderson et al. (1988) reported small, but significant increases in ruminal concentrations of propionate with lasalocid supplementation. There were no effects of supplementation detected in circulating propionate concen- trations in the current experiment or by Quigley et al. (1992). This may be a consequence of the choice of the jugular site for blood sampling. The rumen epithelium metabolizes a portion (10 to 20\%) of absorbed propionate into lactate before release into portal circulation (Bergman, 1990; Kristensen and Harmon, 2004) and would likely alter observed concentrations measured before absorption. A propensity for a near-complete hepatic extraction of portal-derived propionate in ruminating sheep or cattle (Bergman and Wolff, 1971; Weigand et al., 1972; Kristensen and Harmon, 2004) and preruminant calves (Donkin and Armentano, 1995) results in only a small percentage of the original concentration entering peripheral circulation. This probably contributed to the low concentrations $(<0.12 \mathrm{mmol} / \mathrm{L})$ measured throughout this study and in other reports (Quigley et al., 1992; Quigley and Bernard, 1992).

In the preruminant lamb or calf, the ability to metabolize lactate to pyruvate is significantly greater than that in postweaning lambs and calves and adult sheep (Ballard and Oliver, 1965; Savan et al., 1986; Donkin and Armentano, 1995). Circulating concentrations of lactate (Figure 9) or pyruvate (Figure 10) did not appear to be affected by developing rumen function as shown previously by Bartley et al. (1966) and Quigley and Bernard (1992) or ionophore. Concentrations of lactate at 3 to $4 \mathrm{wk}$ of age in this study $(1.3 \mathrm{mmol} / \mathrm{L})$ agree with concentrations ( 1.0 to $1.3 \mathrm{mmol} / \mathrm{L}$ ) measured in the vena cava in calves of the same age by Ortigues et al. (1996). Lactate concentrations across 16 wk of age in calves differed from the gradual decline (3.0 to 1.1 $\mathrm{mmol} / \mathrm{L}$ from wk 1 to 16 ) in lactate concentrations as calves aged reported by Quigley and Bernard (1992). Figure 9 shows a lower initial concentration than reported by Quigley and Bernard (1992), and then a slight increase postweaning. This apparent elevation of lactate and pyruvate after wk 10 coincides with the decline in propionate concentration. A possible explanation would be the substantially reduced rate of hepatic gluconeogenesis from lactate in the ruminant calf (Donkin and Armentano, 1995) due to decreased lactate dehydrogenase and pyruvate carboxylase activity (Edwards et al., 1975; Warnes et al., 1977) and a concomitant increase in hepatic gluconeogenesis from propionate.

Similar to glucose concentrations, circulating NEFA declined with age. Circulating concentrations of NEFA are negatively correlated with intake of solid feed by the preruminant calf (Quigley, 1996). This is presumably in response to the shift in nutrient composition from a diet of high fat and low carbohydrate to one of low fat and high carbohydrate. Measured plasma NEFA concentrations in this experiment (Figure 3) agree with other reports of pre- (Quigley and Bernard, 1992; Ortigues et al., 1996; Stanley et al., 2002) and postweaning 
concentrations (Leat, 1970; Quigley and Bernard, 1992). However, in contrast to the current study, Quigley et al. (1992) reported that calves receiving lasalocid in milk replacer or via rumen cannula both had lower postweaning NEFA concentrations than control calves (0.088, 0.101, and $0.133 \mathrm{mmol} / \mathrm{L}$, respectively).

Acetate derived from rumen fermentation is largely unused by hepatic parenchyma, making acetate a substantial source of dietary energy available to extrasplanchnic tissues (Bergman, 1990; Armentano, 1992). Thus, peripheral measures of circulating acetate relate more closely to intake than propionate or butyrate. Acetate constituted over $90 \%$ of VFA measured and changes relative to age and diet exhibited in Figure 6 are similar to those reported by Quigley et al. (1991b). Significantly greater acetate concentrations at wk 7 and 13 in control calves may be an indication of lasalocid mitigating the rate that VFA concentrations increased in TRT calves due to altered microbial populations. This same observation is not possible for butyrate and propionate because of the extensive oxidation and(or) metabolism to ketones and glucose by the rumen epithelium and liver.

Butyrate concentrations, presented in Figure 8, exhibit a delayed response similar to the acetate curve with control calves having greater concentrations than TRT when weaned at $7 \mathrm{wk}$ of age. Due to extensive rumen epithelial metabolism of butyrate to ketones, changes in plasma butyrate following weaning more closely resembled those described for propionate compared with acetate. Butyrate concentrations reported by Quigley et al. (1991b) were greater than those presented in Figure 8 and did not decline postweaning. However, data from the same study, but published separately by Quigley et al. (1991a), showed BHBA concentrations in late-weaned calves (which were on a comparable timeline as this study) approximately $200 \mu \mathrm{mol} /$ $\mathrm{L}$ lower than those presented in Figure 5. Butyrate has been estimated to be the source of 80 to $95 \%$ of BHBA released by the rumen (Leng and West, 1969).

As the reduced form of AcAc, BHBA is the main circulating ketone in ruminants (Bergman, 1971). Measured concentrations of BHBA in this study correspond to other published values for preruminants (Varnam et al., 1978; Quigley et al., 1991a) and were below 0.2 $\mathrm{mmol} / \mathrm{L}$ before initiation of dry feed intake. After wk 5, an abrupt increase in BHBA concentrations for both diet groups is apparent. Concentrations of BHBA at 8 and $9 \mathrm{wk}$ of age were significantly higher in control than TRT (Figure 5) and agreed with the greater concentration of BHBA reported by Quigley et al. (1992) in control calves compared with those receiving lasalocid. The effect lasalocid had on BHBA concentrations over the 16 -wk period resembled changes described for buty- rate and acetate, with the ionophore mitigating the sharp increase in circulating concentrations resulting from the onset of rumen fermentation. Quigley et al. (1992) also reported lower postweaning ruminal butyrate concentrations in calves receiving lasalocid supplement over controls. This could explain the observed effect in the reduced circulating BHBA concentrations in ionophore-supplemented calves. Conversely, Krehbiel et al. (1992) demonstrated that an increasing ruminal butyrate concentration was associated with an increase in portal-drained viscera flux of AcAc, but not BHBA. This is likely due to the mitochondrial location of BHBA dehydrogenase in rumen epithelium and saturation at high levels of butyrate (Leighton et al., 1983).

Ruminants are generally more insulin-resistant than nonruminants (Brockman, 1986; Weekes, 1991) and the role of glucagon is less clear in ruminants. Insulin measurements in the present study were variable and difficult to interpret (Figure 11), but glucagon concentrations increased at weaning (Figure 12). The adult ruminant liver is glucogenic instead of glycogenic and is less sensitive to acute changes in insulin concentration (Fahey and Berger, 1993). Hepatocytes from ruminating calves were less sensitive to glucagon and lost all sensitivity to insulin during the transition from preruminant to ruminant (Donkin and Armentano, 1995). Stanley et al. (2002) reported postweaning glucagon concentrations in 8-wk-old Jersey calves of $24.96 \mathrm{pmol} /$ $\mathrm{L}$ in agreement with findings of this experiment. This increase of glucagon to a maximum at 8 to $10 \mathrm{wk}$ of age coincides with the nadir of glucose, the decrease in NEFA (indicating no hepatic oxidation of lipid reserves), and the peak in propionate and butyrate concentrations. This reflects the calves' overall shift toward a dependency on gluconeogenesis as it develops into a functioning ruminant.

\section{CONCLUSIONS}

Measurements of blood metabolites in young calves demonstrated changes characteristic of rumen development and metabolism. Declines in glucose and NEFA along with rapid increases in blood VFA and ketones coinciding with initiation of dry feed intake occurred as expected. Feeding calf starter supplemented with lasalocid at levels used to prevent coccidiosis in calves during the preweaning adaptation period and postweaning delayed maximum acetate and butyrate concentrations and concomitantly lowered peak BHBA concentrations. Consumption of starter containing lasalocid resulted in no detectable improvement on the performance characteristics of average daily gain or feed efficiency for this size sample population and seemed to result in slightly lower weekly body weights. 
Thus, feeding a calf starter supplemented with lasalocid for coccidiosis does not appear to have any additional advantages in the form of improved postweaning growth or efficiency through wk 16, but may have an effect on metabolic transition at weaning. This may facilitate the adaptation from a preruminant to a ruminant metabolism by reducing the potential for energy loss through sudden influx of VFA and concomitant ketones.

\section{ACKNOWLEDGMENTS}

The authors gratefully acknowledge the dedicated support of H. Dowlen, P. Lunn, H. Moorehead, and T. Austin of the Dairy Experiment Station (Lewisburg, TN) in the daily management, care, and oversight of the calves. Contributions made by L. Miller, N. Rohrbach, and T. Sun for their technical assistance, and A. Reed for statistical consulting are also gratefully acknowledged.

\section{REFERENCES}

Anderson, K. L., T. G. Nagaraja, J. L. Morrill, P. G. Reddy, T. B. Avery, and N. V. Anderson. 1988. Performance and ruminal changes of early-weaned calves fed lasalocid. J. Anim. Sci. 66:806-813.

Ankom Technology. 2003a. Method for determining acid detergent fiber. Ankom Technology Corp., Macedon, NY.

Ankom Technology. 2003b. Method for determining neutral detergent fiber. Ankom Technology Corp., Macedon, NY.

AOAC. 1999. Official Methods of Analysis. 15th ed. Association of Official Analytical Chemists, Arlington, VA.

Armentano, L. E. 1992. Ruminant hepatic metabolism of volatile fatty acids, lactate and pyruvate. J. Nutr. 122:838-842.

Ballard, F. J., and I. T. Oliver. 1965. Carbohydrate metabolism in liver from foetal and neonatal sheep. Biochem. J. 95:191-200.

Bartley, J. C., R. A. Freedland, and A. L. Black. 1966. Effect of aging and glucose loading on the activities of glucose-6-phosphatase and phosphorylase of livers of cows and calves. Am. J. Vet. Res. 27:1243-1248.

Benson, J. A., C. K. Reynolds, P. C. Aikman, B. Lupoli, and D. E. Beever. 2002. Effects of abomasal vegetable oil infusion on splanchnic nutrient metabolism in lactating dairy cows. J. Dairy Sci. 85:1804-1814.

Bergen, W. G., and D. B. Bates. 1984. Ionophores: Their effect on production efficiency and mode of action. J. Anim. Sci. 58:1465-1483.

Bergman, E. N. 1971. Hyperketonemia-ketogenesis and ketone body metabolism. J. Dairy Sci. 54:936-948.

Bergman, E. N. 1984. Disorders of carbohydrate and fat metabolism. Pages 412-419 in Dukes' Physiology of Domestic Animals. 10th ed. M. J. Swenson, ed. Cornell Univ. Press, Ithaca, NY.

Bergman, E. N. 1990. Energy contributions of volatile fatty acids from the gastrointestinal tract in various species. Physiol. Rev. 70:567-590.

Bergman, E. N., and J. E. Wolff. 1971. Metabolism of volatile fatty acids by liver and portal-drained viscera in sheep. Am. J. Physiol. 221:586-592.

Brockman, R. P. 1986. Pancreatic and adrenal hormonal regulation of metabolism. Pages 405-419 in Control of Digestion and Metabolism in Ruminants. L. P. Milligan, W. L. Grovum, and A. Dobson, ed. Prentice-Hall, Englewood Cliffs, NJ.

Chalupa, W. 1980. Chemical control of rumen microbial metabolism. Pages 325-347 in Digestive Physiology and Metabolism in Rumi- nants. Y. Ruckebusch and P. Thivend, ed. Avi Publishing Co. Inc., Westport, CT.

Donkin, S. S., and L. E. Armentano. 1995. Insulin and glucagon regulation of gluconeogenesis in preruminating and ruminating bovine. J. Anim. Sci. 73:546-551.

Edwards, E. M., U. K. Dhand, M. K. Jeacock, and D. A. L. Shepard. 1975. Activities of enzymes concerned with pyruvate and oxaloacetate metabolism in the heart and liver of developing sheep. Biochim. Biophys. Acta 399:217-227.

Eicher-Pruiett, S. D., J. L. Morrill, T. G. Nagaraja, J. J. Higgins, N. V. Anderson, and P. G. Reddy. 1992. Response of young dairy calves with lasalocid delivery varied in feed sources. J. Dairy Sci. 75:857-862.

Fahey, G. C., and L. L. Berger. 1993. Carbohydrate nutrition of ruminants. Pages 269-297 in The Ruminant Animal, Digestive Physiology and Nutrition. D. C. Church, ed. Waveland Press, Inc., Prospect Heights, IL.

Giesecke, D., U. Beck, S. Wiesmayr, and M. Stangassinger. 1979. The effect of rumen epithelial development on metabolic activities and ketogenesis by the tissue in vitro. Comp. Biochem. Physiol. 62B:459-463.

Krehbiel, C. R., D. L. Harmon, and J. E. Schnieder. 1992. Effect of increasing ruminal butyrate on portal and hepatic nutrient flux in steers. J. Anim. Sci. 70:904-914.

Kristensen, N. B., and D. L. Harmon. 2004. Splanchnic metabolism of volatile fatty acids absorbed from the washed reticulorumen of steers. J. Anim. Sci. 82:2033-2042.

Lane, M. A., R. L. Baldwin, and B. W. Jesse. 2000. Sheep rumen metabolic developments in response to age and dietary treatments. J. Anim. Sci. 78:1990-1996.

Leat, W. M. F. 1970. Carbohydrate and lipid metabolism in the ruminant during post-natal development. Pages 211-222 in Physiology of Digestion and Metabolism in the Ruminant. A. T. Phillipson, ed. Oriel Press, Ltd., Newcastle upon Tyne, UK.

Leighton, B., A. R. Nicholas, and C. I. Pogson. 1983. The pathway of ketogenesis in rumen epithelium of the sheep. Biochem. J. 216:769-772.

Leng, R. A. 1965. Ketone body metabolism in normal and underfed pregnant sheep and in pregnancy toxaemia. Res. Vet. Sci. 6:433-441.

Leng, R. A., and C. E. West. 1969. Contribution of acetate, butyrate, palmitate, stearate, and oleate to ketone body synthesis in sheep. Res. Vet. Sci. 10:57-63.

McGuffey, R. K., L. F. Richardson, and J. I. D. Wilkinson. 2001. Ionophores for dairy cattle: Current status and future outlook. J. Dairy Sci. 84(E. Suppl.):E194-E203.

Mellanby, J., and D. H. Williamson. 1974. Acetoacetate. Pages 1840 1843 in Methods of Enzymatic Analysis. Vol. 4. 2nd ed. H. U. Bergmeyer, ed. Verloh und Chemie, Berlin, Germany.

NRC. 2001. Nutrient Requirements of Dairy Cattle. 7th rev. ed. National Academy Press, Washington, DC.

Ortigues, I., C. Martin, and D. Durand. 1996. Circadian changes in net nutrient fluxes across the portal-drained viscera, the liver, and the hindquarters in preruminant calves. J. Anim. Sci. 74:895-907.

Quigley, J. D., III. 1996. Influence of weaning method on growth, intake, and selected blood metabolites in Jersey calves. J. Dairy Sci. 79:2255-2260.

Quigley, J. D., III, and J. K. Bernard. 1992. Effects of nutrient source and time of feeding on changes in blood metabolites in young calves. J. Anim. Sci. 70:1543-1549.

Quigley, J. D., III, S. I. Boehms, T. M. Steen, and R. N. Heitmann. 1992. Effects of lasalocid on selected ruminal and blood metabolites in young calves. J. Dairy Sci. 75:2235-2241.

Quigley, J. D., III, L. A. Caldwell, G. D. Sinks, and R. N. Heitmann. 1991a. Changes in blood glucose, nonesterified fatty acids, and ketones in response to weaning and feed intake in young calves. J. Dairy Sci. 74:250-257.

Quigley, J. D., III, Z. P. Smith, and R. N. Heitmann. 1991b. Changes in plasma volatile fatty acids in response to weaning and feed intake in young calves. J. Dairy Sci. 74:258-263. 
Reynolds, P. J., G. B. Huntington, and C. K. Reynolds. 1986. Determination of volatile fatty acids, lactate, and $\beta$-hydroxybutyrate in blood by ion exchange cleanup and gas chromatography. J. Anim. Sci. 63(Suppl. 1):424. (Abstr.)

Russell, J. B., and H. J. Strobel. 1989. Effects of ionophores on ruminal fermentation. Appl. Environ. Microbiol. 55:1-6.

Sakata, T., and H. Tamate. 1976. Effect of intraruminal injection of $\mathrm{n}$-sodium butyrate on the mitotic indices in sheep ruminal epithelium. Tohoku J. Agric. Res. 27:133-135.

Sakata, T., and H. Tamate. 1978. Rumen epithelial cell proliferation accelerated by rapid increase in intraruminal butyrate. J. Dairy Sci. 61:1109-1113.

SAS Institute. 2000. Statistics Software: Version 8. SAS Inst., Inc., Cary, NC.

Savan, P. M. J., M. K. Jeacock, and D. A. L. Shepard. 1986. Gluconeogenesis in foetal, suckling, and weaned lambs: The effect of glucagon. J. Agric. Sci. 106:259-264.

Spears, J. W. 1990. Ionophores and nutrient digestion and absorption in ruminants. J. Nutr. 120:632-638.

Stanley, C. C., C. C. Williams, B. F. Jenny, J. M. Fernandez, H. G. Bateman, II, W. A. Nipper, J. C. Lovejoy, D. T. Gnatt, and G. E. Goodlier. 2002. Effects of feeding milk replacer once versus twice daily on glucose metabolism in Holstein and Jersey calves. J. Dairy Sci. 85:2335-2343.
Steen, T. M., J. D. Quigley, III, R. N. Heitmann, and J. D. Gresham. 1992. Effects of lasalocid and undegradable protein on growth and body composition of Holstein heifers. J. Dairy Sci. 75:2517-2523.

Sutton, J. D., A. D. McGilliard, and N. L. Jacobson. 1963. Functional development of rumen mucosa. I. Absorptive ability. J. Dairy Sci. 46:426-436.

Tamate, H., A. D. McGilliard, N. L. Jacobson, and R. Getty. 1962. Effect of various dietaries on the anatomical development $f$ the stomach in the calf. J. Dairy Sci. 45:408-420.

Varnam, G. C. E., M. K. Jeacock, and D. A. L. Shepherd. 1978. Hepatic ketone-body metabolism in developing sheep and pregnant ewes. Br. J. Nutr. 40:359-367.

Warnes, D. M., R. R. Seamark, and F. J. Ballard. 1977. The appearance of gluconeogenesis at birth in sheep. Biochem. J. 162:627-634.

Weekes, T. E. C. 1991. Hormonal control of glucose metabolism. Pages 183-200 in Physiological Aspects of Digestion and Metabolism in Ruminants. T. Tsuda, Y. Sasaki, and R. Kawashima, ed. Academic Press Inc., New York, NY.

Weigand, E., J. W. Young, and A. D. McGilliard. 1972. Extent of propionate metabolism during absorption from the bovine ruminoreticulum. Biochem. J. 126:201-209.

Williamson, D. H., and J. Mellanby. 1974. D-3-hydroxybutyrate. Pages 1836-1839 in Methods of Enzymatic Analysis. 2nd ed. Vol. 4. H. U. Bergmeyer, ed. Verloh und Chemie, Berlin, Germany. 